\title{
Práticas musicais de jovens \\ e vida cotidiana: socialização e identidades em movimento
}

\author{
Jusamara Souza \\ (UFRCS) \\ Maria de Fatima Quintal de Freitas
}

(UFPR)

\begin{abstract}
Resumo: Este artigo aborda questões vinculadas a práticas musicais de jovens que vivenciam a música com diferentes mídias. Tomando a perspectiva teórica dos estudos sobre a vida cotidiana, o objetivo é analisar discursos, conceitos, métodos e resultados da produção de conhecimento musical específicos da juventude quando mediados pelas tecnologias. Dentre os aspectos analisados destaca-se a formação de identidades e socialização considerando a música como um signo geracional. Essas categorias contribuem para uma compreensão empiricamente fundamentada sobre o papel que as mídias exercem para os jovens em suas aprendizagens musicais. As reflexões e análises permitem uma compreensão ampliada das interfaces entre música, educação e identidades sociais.
\end{abstract}

Palavras-chave: juventude; identidade musical; socialização musical; vida cotidiana.

YOUTH MUSICAL PRACTICES AND EVERYDAY LIFE: SOCIALIZATION AND IDENTITIES IN MOTION

\begin{abstract}
This study focuses on issues associated with the musical practices of young people that experience music with the use of different media. Based on the theoretical perspective of studies on everyday life, the main objective is to analyze speeches, concepts, methods and results in the production of musical knowledge by youngsters when mediated by technologies. Special attention is given to the formation of identities and socialization, considering music as a generation sign. These categories contribute to an empirical understanding based on the role played by the media in the young people's musical learning. The reflections and analyses allow a broad understanding of the interfaces between music education and social identities.
\end{abstract}

Keywords: youth; musical identity; musical socialization musical; everyday life. 


\section{Introdução}

Nos últimos anos, tem se ampliado de maneira significativa os estudos dirigidos à compreensão de problemáticas que têm como foco central a juventude e suas relações com diferentes áreas e, entre elas, com a música. Na área de educação musical, merece destaque a pesquisa documental sobre "Juventude e música" coordenada por Margarete Arroyo, desenvolvida em várias fases. ${ }^{1}$ Nesta pesquisa, foram catalogados 86 textos produzidos em diferentes programas de pós-graduação brasileiros e elaborados 48 comentários bibliográficos. ${ }^{2} \mathrm{~A}$ interface da juventude com música tem sido contemplada também em outros levantamentos bibliográficos feitos por outras áreas, entre as quais, educação (Hayashi, Hayashi e Martinez, 2008; Spósito, 2009) e psicologia social (Zanella et. al., 2013; Maheirie et al., 2013). Isto não revela tão somente um interesse de investigações acadêmicas, mas um compromisso em captar desafios e contradições no cenário da vida cotidiana contemporânea no que diz respeito ao envolvimento dos jovens com a música.

Particularmente tem nos interessado discutir questões sobre essa temática, buscando o entendimento das práticas musicais que integram o cotidiano de jovens que passam por diferentes processos de exclusão no mundo contemporâneo. Como a música está presente? Que sentido tem a música para essas pessoas? Que elementos musicais integram seu cotidiano, que processos utilizam informalmente para aprender música e quais os aspectos relevantes destas práticas? Como a música e as mídias ${ }^{3}$, como transmissores de cultura, afetam a

\footnotetext{
1 Ver Arroyo e Jantzen, 2007; Jantzen, 2007; Nascimento, 2008, Nascimento e Arroyo, 2008 e Arroyo, 2009.

${ }^{2} \mathrm{O}$ relatório final encontra-se disponível em: www.seer.ufu.br/index.php/horizontecientifico/article/viewFile/.../2906, acesso em $13 / 06 / 2014$, e o trabalho ampliado no formato de livro, publicado pela Editora Unesp (Arroyo, 2013).

3 Geralmente quando falamos de mídias, reportamo-nos a aparelhos técnicos com dispositivos para armazenar, reproduzir ou transmitir conteúdos e informações. Porém, é necessário lembrar que cada mídia possui locais específicos onde é mais utilizada e que sua feitura técnica também determina as formas de recepção e a que necessidades sociais responde. Há mídias de fácil transporte, como rádio, MP3 e iPods; há mídias mais estáticas, como a televisão; mídias puramente auditivas que possibilitam outras formas de recepção do que as audiovisuais; entre outras.
} 
vida dos jovens e as políticas de escolarização? As mídias, consideradas aqui como meios de comunicação, estão cada vez mais presentes na vida dos jovens. Hoje, o convívio com celulares, iPods, tablets, TV e computadores representam componentes importantes de suas vidas para a busca de identidade e a socialização. Como os jovens estão utilizando as novas mídias para compreenderem a si mesmos e aos seus pertencimentos sociais, e como as mídias os acompanham no dia a dia? As análises dessas questões têm sido desenvolvidas em nossas pesquisas (Souza, 2004, 2008, 2011a, 2011b; Freitas, 2008a, 2008b) e também nos projetos de mestrado e doutorado por nós orientados, tendo como arcabouço teórico as teorias da vida cotidiana.

Este artigo aborda, particularmente, questões vinculadas à socialização e à construção de identidade mediadas pela música na vida cotidiana, com o objetivo de contribuir para a compreensão de problemas específicos no âmbito da música, educação, juventudes e mídia.

Mas de que juventudes estamos falando? E, de que dinâmicas juvenis e em que espaços sociais estamos nos referindo? Considerando a juventude como uma categoria construída social e historicamente, podemos afirmar que as características etárias, por si só, não dão solidez para sua constituição, devendo ser, também, considerados aspectos oriundos de várias áreas, como a psicologia social e ciências sociais. Como vários autores (Bourdieu, 2000; Carrano, 2000 e Groppo, 2010), pensamos que poderia ser uma certa armadilha teórica tanto falar em juventude no singular, como falar em comportamentos e práticas como sendo exclusivas de uma etapa biologicamente definida por sua idade. Na realidade são práticas construídas socialmente e relativas ao tempo e cenário históricos nos quais acontecem.

Ao abordamos as práticas musicais, considerando-as socialmente construídas e mesmo que tenham uma realização mais frequente por parte dos jovens, pretendemos também apontar algumas reflexões a respeito de dimensões psicossociais presentes nessas interações estabelecidas. Ou seja, quando falamos de dinâmicas juvenis, isto não deveria significar que são, obrigatoriamente, sempre pessoas com uma faixa etária equivalente àquela que é caracterizada como da juventude. Em verdade, chama-se a atenção para o fato de que podem 
ser práticas, atitudes e valores típicos dos jovens ocorrendo em outras dinâmicas e contextos considerados juvenis. Assim, concordamos com Margulis e Urresti (1996) que as maneiras de ser jovem são condicionadas por distintos marcos sociais e se manifestam de formas desiguais. Portanto, as modalidades de ser jovem dependem de critérios como geração, gênero, raça e classe social.

Iniciamos o artigo com reflexões sobre a onipresença da música na sociedade contemporânea e o significado do desenvolvimento tecnológico para a construção de relações entre jovens e práticas musicais. Na segunda parte destacamos pontos relevantes da discussão sobre a concepção de juventude e do ser jovem a partir da literatura disponível. Nas seções seguintes, terceira e quarta partes, discutimos a participação das mídias na socialização de jovens e a constituição de suas identidades sociais e musicais. Finalmente, apresentamos a síntese das ideias discutidas e suas contribuições.

\section{Músicas e tecnologias na vida cotidiana}

A música faz parte do nosso dia a dia de múltiplas formas: como espetáculo "ao vivo", shows de cantores ou como videoclipe, com a audição do rádio e suas diversas programações, na escuta de CDs, DVDs, aparelhos portáteis, celulares e computadores, com a audiência da TV e seus diversos programas, como trilha sonora de novelas ou filmes ou como parte da propaganda e programação televisiva ou radiofônica. Através dos diversos meios eletrônicos, a relação da música e seus consumidores/produtores é repensada e apresenta-se cada vez mais de uma forma interativa, na qual as pessoas buscam maneiras de participação, compartilhamento e aprendizagem. Além disso, os meios eletrônicos tornam-se aparatos tecnológicos que auxiliam e facilitam o processo de criação e produção musical. Como Schläbitz (1996) analisa, “as novas mídias, as novas tecnologias mostram-se como elementos de diálogo em nosso mundo cotidiano e, no domínio da música, como instrumentos que estimulam a criatividade" (p. 8). No momento em que disponibilizam novas maneiras e recursos para se fazer e reproduzir 
música, as novas mídias estariam conferindo à música uma "nova e possivelmente dominante posição na vida das pessoas" (Schläbitz, 1996, p. 7).

O desenvolvimento tecnológico não só proporcionou novas formas de produção e divulgação musical, como também diversificou os modos de entretenimento e apropriação musical na sociedade. Por exemplo, as tecnologias de digitalização e difusão de músicas através da internet e, por sua vez, a apropriação dessa tecnologia pelos artistas conduziram a uma mudança na forma de produção e veiculação de suas músicas. Tais aspectos transformaram a cadeia produtiva da música, desde a sua composição/criação, venda e difusão/circulação até o consumo. A disponibilização de músicas na internet e nas redes sociais tornou as práticas musicais mais acessíveis e interativas.

Assim, o acesso quase ilimitado à música, promovido pelas tecnologias, faz com que os jovens sejam consumidores criativos, tornando-se ao mesmo tempo receptores e produtores, levando autores como Garcia Canclini e Urteaga (2012, p. 194) a criar a palavra "prosumidores", termo que se refere à síntese entre as expressões "produtores" e "consumidores". A superoferta de música na internet, com acessos e downloads gratuitos (ou não) criam redes de compartilhamento e comunidades virtuais que se afinam pelas preferências musicais. As conexões em tempo real permitem não apenas o acesso a obras musicais e informações sobre músicos mas também o fazer música juntos, seja criando, improvisando ou executando repertórios já conhecidos e disponíveis. Daí muitos autores afirmarem que vivemos numa "sociedade musical".

Temos hoje uma parcela importante da sociedade, cuja faixa etária está entre 12 e 24 anos e acima dos 25 ou 30 anos, que emprega em seu dia a dia inúmeras tecnologias e artefatos derivados do desenvolvimento eletro-eletrônico. Entre tais usos que têm sido feitos encontram-se: as redes sociais e os foruns/chats de conversas online (seja acessando-as diretamente em seus equipamentos móveis, seja indo a lan-houses para acedê-las ou ter suas conversas no skype e outros fóruns); as variadas multi-funções dos telefones móveis, viabilizando os incontáveis selfies que circulam virtualmente; o uso desses artefatos para atividades e funções cotidianas (como por exemplo, ouvir música, servir de despertador; com alertas sonoros em agendas virtuais indicando mudança de 
atividade ou compromissos; gravações de aulas e outros; os acessos e arquivamentos em pastas/arquivos-nuvem que contribuem para que tenham sempre disponíveis, como uma espécie de "escritórios móveis", os textos, documentos, imagens e músicas que são importantes.

Esta espécie de "escritório-casa" (com características virtuais e acesso permanente e imediato) apresenta algumas funções psicossociais importantes, como: integrar o espaço público e o privado, trazendo sentimentos de estar sempre atualizado, sempre "antenado" com o mundo (ou com aquilo que considera importante para esse mundo público que ele se aproprie em seu mundo privado); ter um sentimento de ser atual e moderno e, por isso mesmo, sentir-se jovem; possibilitar contato amplo com inúmeras pessoas, haja vista a quantidade de "curtições" e acessos que cada facebook tem diariamente; estabelecer fronteiras vagas e difusas entre o que se circunscreve ao domínio da vida pública e ao da vida privada, criando fronteiras tênues entre elas.

A respeito do lugar da mídia e mundo virtual (e seus impactos) na vida cotidiana, que mostra a materialidade do mundo vivido se realizando também pela mediação do mundo virtual e pela "presentificação" que a tecnologia gera, recorremos à explicação de Berger e Luckmann:

A realidade da vida cotidiana está organizada em torno do "aqui" de meu corpo e do "agora" do meu presente. Este "aqui e agora" é o foco de minha atenção à realidade da vida cotidiana. Aquilo que é "aqui e agora" apresentado a mim na vida cotidiana é o realissimum de minha consciência. A realidade da vida diária, porém, não se esgota nessas presenças imediatas, mas abraça fenômenos que não estão presentes "aqui e agora". Isto quer dizer que experimento a vida cotidiana em diferentes graus de aproximação e distância, espacial e temporalmente (Berger; Luckmann, 1983, p. 39).

As inovações no campo das mídias presenciais (rádio, TV, CDs) e virtuais (internet, arquivos digitais sonoros) trazem também mudanças cada vez mais dinâmicas no plano técnico e de conteúdo na música. Em decorrência, as formas como os jovens interagem com a música tornam-se cada vez mais complexas. Para Münch, "um veloz crescimento de ofertas midiáticas tornou possível o que em cem anos ainda era inimaginável: via antena, cabo e satélite, está à disposição um 
número infinito de ofertas musicais transmitidas pelos meios de comunicação de massa” (Münch, 1997, p. 383). Assim, segundo Tagg (1990, apud Münch, 1997. p. 383) o contato com milhões de músicas faz com que, "hoje em dia, crianças de 8 anos já tiveram mais contato com a música do que seus bisavós, durante toda sua vida."

Se a música transmitida pelas mídias é, hoje, parte inerente e inquestionável do cotidiano dos jovens (Castro, 2007) e se as novas ofertas midiáticas são aceitas com extrema facilidade (Garcia Canclini; Urteaga, 2012), como interrogar as diferentes "culturas juvenis" contemporâneas compreendidas como "comunidades de sentido" múltiplas, diversas e possuidoras de saberes e sensibilidades próprias? (Herschmann, 1996, p. 57)

Como lembra Bourdieu (2000), é difícil falar dos jovens como uma unidade social, como um grupo dotado de interesses comuns. Dessa perspectiva, a análise das questões juvenis passa mais pelas diferenças, incluindo o pertencimento de classe, gênero, idade e etnia. De acordo com Menandro e Trindade (2009), é reconhecer que o jovem, “integra uma classe social, pertence a um gênero, possui características étnicas, vive em um contexto cultural específico" e que o modelo de juventude "como etapa universal, natural, inevitavelmente vivida a partir de conflitos e comportamentos que the são inerentes, possivelmente não corresponde ao que é vivido por muitos jovens [...]. Muitos adolescentes brasileiros, vários dos quais sequer frequentam a escola, não se reconheceriam nesse modelo" (Menandro; Trindade, 2009, p. 25).

Considerando que as juventudes pertencem a contextos específicos, por certo a análise das práticas musicais não poderá se eximir de analisar as condições em que essas práticas acontecem.

\section{Juventudes e práticas musicais}

$\mathrm{Na}$ concepção das abordagens socioculturais juventude deve ser entendido no plural, visto que os jovens travam relações em espaços sóciohistóricos diferentes, constroem percursos identitários que são embasados por 
diferentes valores, crenças e concepções que mudam constantemente, o que permite dizer que eles vivenciam uma pluralidade de trajetórias individuais e sociais, que não são nem universais e nem padronizadas. Como Margulis e Urresti escrevem:

A condição de juventude, em suas distintas modalidades de expressão, não pode ser reduzida apenas a um setor social ou separada das instituições [a escola, o trabalho, as instituições religiosas, os partidos políticos, os clubes e associações, entre outros] como se tratasse de um ator dividido, separado do mundo social ou apenas atuante como sujeito autônomo (Margulis: Urresti, 1996, p. 30, tradução nossa).

Vários tem sido, nos últimos anos, estudos e pesquisas que ao tomarem como foco central a juventude, deparam-se, também, com os aspectos culturais e artísticos como sendo mais uma dimensão, não apenas valorizada pelos jovens em seus depoimentos, mas também dotada de sentidos e valores que emergem do cotidiano das pessoas. Entre tais aspectos a música tem merecido destaque nesses estudos por diferentes razões como: ser recorrentemente mencionada nos depoimentos dos jovens de diferentes camadas sociais (Dayrell, 2005; Quaresma, 2013); estar presente em práticas cotidianas de mulheres jovens (Weller, 2005); estar correlacionada com as questões de raça (Lima, 2002) e idade (Ribas, 2008) mesmo que com distintos matizes e finalidades; contribuir para o fortalecimento ou a partilha de situações de prazer e interações sócio-afetivas positivas.

O entendimento da juventude como sendo um grupo heterogêneo tem contribuído para que, ao se lidar com práticas musicais, estas sejam interpretadas em suas correlações com instituições educativas, religião, família e trabalho. Entre os diversos estudos que tem gerado tais interfaces entre música e juventude, mencionamos aqui uma pesquisa, cujas análises e aprofundamentos realizados por três psicólogas sociais (Menandro: Trindade: Almeida, 2010) permitiram mapear e compreender os diversos significados que a categoria juventude/adolescência teve ao longo de algumas décadas no Brasil. Partindo do pressuposto de que os relatos veiculados em meios de comunicação indicam de algum modo as visões, tendências e opiniões daqueles que os lêem. Menandro, Trindade e Almeida (2010) analisaram as matérias sobre juventude/adolescência veiculadas por uma 
mesma revista em 653 textos, publicados em dois momentos diferentes da história brasileira: de 1968 a 1974 e de 1996 a 2002.

Embora a música não tenha sido o foco central nessa investigação, ela aparece como tendo um significado importante associado à categoria juventude. Ou seja, entre as representações que são atribuídas à juventude, nos textos jornalísticos, em especial no segundo período, aparecem significados ligados a duas classes principais de representações: uma, ligada à "adolescência: necessidade de proteção", onde se localizariam os cuidados com criação, prevenção e educação e futuro; e a segunda, ligada à "adolescência e ruptura" (Menandro; Trindade; Almeida, 2010, p. 117), em que se localizariam os contextos de compromisso com o prazer, vulnerabilidade, e violência. Dentre as várias representações atribuídas aos jovens nessa situação - como moda, sucesso, roupa, pertencimento a diferentes "tribos", entre outros - é que a música aparece, nesse contexto do compromisso com o prazer, indicando uma forte associação, como bem assinalam Menandro, Trindade e Almeida (2010, p. 117), visto que os jovens "encontram na música uma de suas maiores fontes de diversão" por ser considerada "também como um meio através do qual" eles podem expressar "seu modo de pensar", e explicam:

Sua preferência musical recai sobre aqueles estilos em que encontram retratados aspectos de seu cotidiano e que tratam temas com os quais se identificam, em alguns casos com grandes doses de irreverência em suas letras. Rap, funk e principalmente o rock atraem a atenção dos adolescentes (Menandro; Trindade; Almeida, 2010, p. 137).

A expansão da oferta musical pelos meios de comunicação levou vários pesquisadores no Brasil a se dedicarem a estudos sobre gosto musical de jovens e construção de identidades (Oliveira, 2012; Moura, 2009). Em um trabalho anterior Souza (2004) apontava para a formação de grupos destacando a identificação dos jovens

com suas tribos musicais (com o moto: diga-me o que tu ouves e eu te direi quem tu és) frequentando os espaços multiculturais na cidade, como shows de música sertaneja/caipira/country, e lugares como boates, onde se 
sincronizam com o rock, a tecno music, o hip hop, a música "pop” como o axé-music, pagode, etc. (Souza, 2004, p. 10).

Acrescentava ainda a autora: “Com os estilos de música eles expressam também sentidos da cultura juvenil, manifestados no vestir, no comportar, no corpo, na linguagem e gestos, revelando a identidade: são pagodeiros, neosertanejos, roqueiros, etc." (Souza, 2004, p. 10).

Assim, se há uma década atrás podíamos falar em constituição de "tribos" musicais fechadas ou pouco permeáveis a outros estilos musicais, recentes pesquisas mostram que os jovens ouvem música de todos os estilos e épocas (Barbosa; Veloso; Dubeux, 2012). Os depoimentos mencionam uma escuta eclética como de um jovem de 28 anos, que diz escutar com frequência "tudo que é tipo de música, direto, direto, pagode, country, hip hop, dancing, música brasileira e funk" (Ribas, 2008, p. 150). É possível que a tecnologia venha contribuindo para a tolerância de repertórios muito diversos. Ou seja, a tecnologia estaria permitindo uma mescla maior de gêneros musicais o que levaria a uma convivência e variedade maior de repertórios, especialmente para os jovens. Como relata uma jovem de 18 anos:

Penso a minha vida a partir da música. Para cada coisa que faço preciso da música certa, e tem que ser aquela, senão a coisa não parece real (in: Barbosa; Veloso; Dubeux, 2012, p. 52).

Várias pesquisas tem demonstrado também que a música é existencialmente necessária para os jovens. É frequente nos depoimentos a ideia de que eles passam “o dia inteiro com música” (Schmeling, 2005, p. 60) e que sem a música não poderiam viver. Isso pode ser, por exemplo, visto nas palavras de um jovem de 25 anos: "Eu não posso imaginar minha vida sem música, ela me preenche, me emociona, me faz chorar, me anima. É a primeira coisa que faço ao acordar" (in: Barbosa; Veloso; Dubeux, 2012, p. 52). 


\section{Socialização: juventudes e apropriação ativa dos meios de comunicação}

A popularidade e a multifuncionalidade das mídias na vida musical dos jovens de hoje tem sido abordadas por vários estudos (Schläbtiz, 1996; Baacke, 1998; Münch, 1998; Stålhammar, 2004; Garcia Canclini e Urteaga, 2012; Garcia Canclini, Cruces e Castro Pozo, 2012, entre outros). Schläbitz (1996), ao examinar a importância das novas tecnologias para o ensino da música, destaca a presença das mídias na vida dos jovens, e afirma que essas mídias assumiram a tarefa de ajudá-los "a se integrarem na sociedade" (p. 361). As mídias hoje representam importantes componentes do cotidiano e se estabelecem como uma instância de socialização relevante para os jovens (Souza, 2011a).

O processo de socialização pode ser visto, segundo Setton (2002), "como um espaço plural de múltiplas relações sociais. Pode ser considerado como um campo estruturado pelas relações dinâmicas entre instituições e agentes sociais distintamente posicionados em função de sua visibilidade e recursos disponíveis" (p. 109). Setton (2012), tem colocado a necessidade de serem realizados estudos que levem em conta os impactos da mídia nas dimensões da socialização e das produções culturais, definindo as mídias da seguinte maneira:

Entendo por mídias a produção cultural, material, tecnológica e simbólica, eletrônica ou digital, divulgada pelo conjunto de instituições da indústria editorial, fonográfica, televisiva, radiofônica, cinematográfica e a publicidade que possibilita a maior circulação de referências de estilos identitários (Setton, 2012, p. 54).

Discutindo a socialização de jovens pelas mídias Vollbrecht, Ferchhoff, e Baacke (1997) enfocam que "mundo de vida" (Lebenswelt) é o ambiente no qual o ser humano realiza suas "reais experiências e possibilidades de ação". Ele pode ser constituído por uma pessoa, bem como por um grupo de pessoas, como por exemplo, a família, a escola, os amigos, entre outros. Nestes espaços e/ou grupos se desenvolvem a educação e a socialização. A rotina, "a estrutura das ações 
repetitivas", como os afazeres cotidianos, assim como momentos especiais (festas e comemorações) levam à descrição do mundo da vida, como "mundo cotidiano."

No caso dos jovens, eles estabelecem relações sociais e culturais em diferentes espaços e meios de socialização: no lugar em que residem, no bairro em que vivem, no grupo social e de amigos e, em diversas formas de lazer utilizadas no tempo livre, nos locais de práticas esportivas, na rua, no shopping, nos lugares de entretenimento da cidade, como os de grandes eventos e festas coletivas. Como citado em outro artigo:

Nesses locais, é frequente a expressão festiva do coletivo, o desejo do encontro do jovem adolescente, de ser visto e ver, identificar e socializar-se, marcando entre grupos e seus pares suas semelhanças e divergências, assumindo-se como seres sociais complexos e contraditórios (Souza, 2004, p. 10).

No que diz respeito às mídias, para Kübler (2003), os jovens caracterizamse por serem pioneiros nas descobertas, no manuseio e utilização de novidades. Por exemplo, na música digital e na internet, na maioria dos casos são criativos. As mídias são, como escreve Klüber (2003), "não apenas importantes fatores de socialização dos jovens, portanto como intermediários entre o indivíduo jovem e a sociedade, mas também como veículo de auto-socialização juvenil, como catalisadores do encontro e da determinação do perfil do jovem na condição de indivíduo contemporâneo no aqui e agora social" (p. 20).

Em relação ao campo de análise de estudos sobre os usos da mídia e cultura jovem, as teorias críticas sobre media, globalização e juventude têm pontuado o caráter ideológico de imagens do estilo contemporâneo de vida através dos meios de comunicação. A tese do imperialismo cultural que analisa "o poder simbólico da comunicação mediadas pelos meios de comunicação e os interesse comerciais", por exemplo, tem sido contestada por autores como Thompson (1998, p. 44).

Thompson (1998) defende que existe uma "ativa apropriação" da mídia pelo público, especialmente pelos jovens. Os jovens são altamente seletivos e críticos, capazes de analisar a oferta musical dos meios de comunicação e propor 
outros conteúdos. Portanto, os jovens utilizam as mídias de um modo consciente, e a recepção dos produtos da mídia não se dá de forma passiva, mas sim através de um processo "ativo e criativo". Conforme estudos mais recentes sobre juventudes e redes digitais, como o de Garcia Canclini e Urteaga (2012):

As discussões de trinta anos atrás, nos estudos comunicacionais sobre a não passividade dos espectadores e consumidores, ficam relegadas a segundo plano diante da variedade de comportamentos interativos nos quais os jovens não profissionalizados ainda recriam as ofertas culturais e as reescrevem em cenas, sítios web e ações grupais. (Garcia Canclini; Urteaga, 2012, p. 196, tradução nossa)

As mídias proporcionam novas experiências e novos conhecimentos, viabilizando "experimentar eventos, observar outros e, em geral, conhecer mundos - tanto reais quanto imaginários - situados muito além da esfera de seus encontros diários" (Thompson, 1998, p. 159). Ao receber novos conhecimentos e informações, os indivíduos estão interagindo e reinterpretando estes elementos conforme sua experiência, sua bagagem cultural e história afetivo-emocional.

Ainda segundo Thompson, a interpretação de uma mensagem, seu "significado" ou "sentido" deve ser avaliado como "um fenômeno complexo e mutável, continuamente renovado e, até certo ponto, transformado, pelo próprio processo de recepção, interpretação e reinterpretação. O significado que uma mensagem tem para um indivíduo dependerá em certa medida da estrutura que ele ou ela traz para o sustentar" (Thompson 1998, p. 44-45).

Durante a recepção e apropriação dos conteúdos da mídia, os indivíduos encontram-se "envolvidos num processo de formação pessoal e de autocompreensão - embora em formas nem sempre explícitas e reconhecidas como tais" (Thompson, 1998, p. 45-46). Ao incorporar as mensagens da mídia à própria vida, “o indivíduo está implicitamente construindo uma compreensão de si mesmo, uma consciência daquilo que ele é e de onde ele está situado no tempo e no espaço" (Thompson, 1998, p. 45-46).

Nessa direção, como escrevem Wildermuth e Dalsgaard (2006), a mídia pode ser vista "como um conjunto de recursos que não só facilitam formas de conhecimento social e cultural sobre o mundo, mas também desempenham um 
papel importante na movimentação dos jovens para criar identidades estáveis e significativas para si." A mídia também constitui "um espaço em si mesmo para uma negociação da identidade imbuído de preocupações morais e necessidades de reconhecimento" (Wildermuth e Dalsgaard, 2006, p. 12-13). Muitas pesquisas também mostram que essas identidades são negociadas intersubjetivamente, sob as condições de uma socialização musical mediada pelas tecnologias (Arnett, 1995).

\section{Identidades musicais, juventude e mídias}

Os estudos sobre as identidades sociais, os comportamentos intergrupais e os processos comunicacionais, apoiados nos aportes do campo da psicologia social (Tajfel, 1983; Lane, 1986a,1986b), permitem compreender os processos presentes na interface entre socialização musical e formas subjetivas que interferem nos diferentes processos identitários dos jovens (MacDonald; Hargreaves; Miell, 2009). Desse modo, pode-se dizer que nessa negociação intersubjetiva forjada nas relações e processos grupais, poderia estar uma das razões para o fato das pessoas variarem os tipos de mídias, música e ambientes de estimulação visual e sonora em seu cotidiano. Inicialmente, dir-se-ia que uma das finalidades estaria na própria fruição individual e, eventualmente, em comunicar aos outros esse desfrute ou descoberta. Entretanto, a continuidade e regularidade desse movimento chama a atenção para outro aspecto: a do significado atribuído ao objeto e ao seu desfrute, ou seja, o significado positivo de estar atualizado e de compartilhar um universo comum, simbólico e emocional, com seus pares, mesmo que façam mudanças frequentes nas mídias e seus conteúdos.

De um lado, isto revela um aspecto importante ligado ao fato de que é necessário haver um mínimo de variações nas mídias para que o interesse e a atenção continuem existindo, a fim de que a escuta e seu desfrute não sejam rapidamente abandonados. Por outro, isso também gera um paradoxo visto que contribui para que as interações e possibilidades de constituição de grupo, 
mediados pelos recursos eletrônicos que permitem o compartilhar de informações e conteúdos visuais e imagéticos, possam ser efêmeros e voláteis, sem necessariamente implicar em uma durabilidade que seria esperada em relações cotidianas que vão se enraizando e mostram-se necessárias à construção de identidades sociais (Lane, 1986b; Tajfel, 1983).

Neste momento, pode-se dizer que a midiatização das relações, como apontada pelos jovens quanto ao uso das mídias, parece revelar alguns paradoxos. De um lado, cria a necessidade da variação de informes e conteúdos veiculados, para que haja um aumento de interesses recíprocos (entre as pessoas que se comunicam ou se transmitem diversos conteúdos). De outro, torna essas mesmas relações mais frágeis, visto que os processos de identificação e enraizamento presentes podem ser efêmeros, temporários e vulneráveis a quaisquer variações, não necessariamente levando à construção de uma identidade e sentido grupal (Freitas, 2008b).

Deste modo, a categoria identidade(s) da juventude(s) estaria na dependência de aspectos, muitas vezes episódicos, que fortaleçam a motivação e interesse para se comunicarem, e para encontrarem algum sentido em se manterem reunidos e em interação contínua e regular, através de seus artefatos eletro-eletrônicos. Em outras palavras, significaria dizer que a identidade e coesão desses jovens, embora podendo ter uma grande abrangência devido ao tipo de comunicação rápida e virtual, não necessariamente indica um enraizamento e continuidade dessas interações e relações para além desse contato e dos interesses e/ou conteúdos veiculados (Freitas, 2008a). Entretanto, cabe aqui também mencionar que podem haver relações e interações, possibilitadas através das mídias, que adquirem uma força equivalente àquelas acontecidas face to face, se existirem similitudes e interesses comuns entre os conteúdos veiculados gerando fortes elementos emocionais e afetivos de caráter positivo. Isso significaria a constituição dos processos do in group, em oposição ao out group (Tajfel,1983), em que vários aspectos de categorização e identificação grupal adquirem um peso expressivo.

Nesse sentido, o fato das tecnologias serem mais acessíveis e de uso mais fácil para as gerações mais jovens, traz em si um fator positivo, visto que os 
mantém "conectados", "ligados" e contribui para que se sintam pertencentes àquele grupo, trupe, galera ou tribo com o qual convivem, em alguns momentos, mesmo que possam ter características de grupos fechados e inflexíveis. Isto, se de um lado, mostra um forte sentimento de identificação e pertencimento nas relações intragrupais, de outro também, mostra um certo caráter discriminatório e segregacionista em relação ao "estranho", apresentando um certo processo de "guetificação" nas relações intergrupais. Nesse processo o "outro social", ao ser visto como "estranho" ou "alheio", pode representar um certo grau de perigo ou receber alguma desvalorização, mesmo decorrente de qualquer motivo (representar ameaças em potencial, ignorar o manejo das mídias e tecnologias; ter vergonha por seu desconhecimento, entre outros). Assim, as mídias ao fortalecerem interações que tenham estas significações, podem ter usos e sentidos sociais com um alto potencial seja para a coesão ou para a discriminação nas interações cotidianas.

O significado que a mídia pode trazer para a vida das pessoas em seus cotidianos, dando a sensação de estarem compartilhando várias coisas em comum, é hoje um aspecto importante para a convivência humana. Isto porque, através dela, podem ser construídas aproximações virtuais, fortalecidos sentimentos de pertencimento e, consequentemente, criadas redes virtuais que podem aproximarse da constituição de grupos no mundo real. Constitui-se assim um cenário fundamental para que sejam criadas identidades através destas similitudes compartilhadas. Dessa forma, o "jovem" passa a identificar-se com outros, e um dos aspectos que daria esta visibilidade para haver a identificação seria o ter e saber usar bem os artefatos tecnológicos. Derivado disto, então, os conteúdos veiculados por tais artefatos que têm uma importância crucial. Esta importância manifesta-se, por exemplo, no caso da música, ao ser veiculada e partilhada via media, revelar seu significado emocional, em especial se ela for positivamente percebida e sentida. Esse processo acaba por potencializar o sentimento de pertença e o efeito de agregação e de referência de pares, mesmo que isso se dê no mundo virtual, o que contribui para um "mundo em comum" que passa a ser vivido e compartilhado, como diz Berger e Luckmann (1983): 
A realidade da vida cotidiana [...] apresenta-se a mim como um mundo intersubjetivo, um mundo de que participo juntamente com outros homens. [...] Estou sozinho no mundo dos meus sonhos, mas sei que o mundo da vida cotidiana é tão real para os outros quanto para mim mesmo. De fato, não posso existir na vida cotidiana sem estar continuamente em interação e comunicação com os outros. [...] Meu "aqui" é o "lá" deles. Meu "agora" não se superpõe completamente ao deles. Meus projetos diferem dos deles e podem mesmo entrar em conflito. De todo modo, sei que vivo com eles em um mundo comum (Berger e Luckmann, 1983, p. 40).

A contribuição das mídias para os processos de formação de identidade de jovens é um tema recorrente na literatura. Os meios de comunicação desempenham um papel importante para se criar uma identidade pessoal e cultural, o que faz sentido para eles e outros. Wildermuth e Dalsgaard (2006), por exemplo, analisam:

[...] os meios de comunicação não só proporcionam espaços de identidade, como também permitem a identificação imaginária com a representação dos outros. No nível social, interacional, a mídia também contribui para os processos de formação de identidade pelo próprio ato de afirmar e explicar as preferências e aversões, para o qual as representações culturais e do mundo da vida imaginada são permitidas (Wildermuth e Dalsgaard, 2006, p. 21 ; tradução nossa).

Um outro aspecto liga-se ao fato do "ser jovem", através da música, poder se afirmar de diferentes formas e por vários canais. Na escuta musical, por exemplo, os jovens procuram se identificar e se diferenciar das gerações mais velhas através da audição em volume alto. Ao ouvir música em um volume "máximo" os jovens procuram se diferenciar dos adultos através de outros hábitos de escuta e de outros gêneros musicais como heavy metal e rock. Com muita frequência, esse jeito de ouvir música cria conflitos, especialmente entre jovens e adultos, como traduz o depoimento de um jovem de 14 anos:

[...] Toda reunião de condomínio, reclamam do som Um dia, a vizinha ligou pra minha casa: avisa pro 'marginalzinho' que eu chamei a polícia”. Daí eu, 'bah, pára com isso'. Aí eu desci lá embaixo e fui tirar as caras com ela, e ela não tinha chamado a polícia. Só que ela achou que eu ia bater nela [...], e, daí, ela realmente chamou a policia [...];. Tudo por causa do som! (in: Schmeling 2005, p. 74). 
Nesse caso, a música torna-se um elemento de diferenciação social a partir dos hábitos de ouvir música. Isto é, o modo de ouvir música e a escolha do repertório geram tensionamentos musicais que provocam disputas e conflitos. Neste exemplo, o jovem é visto por um adulto como um “marginalzinho”, que precisa ser repreendido e controlado pela polícia. Esses aspectos mostram que práticas mediadas pela tecnologia podem contribuir para uma espécie de “segregação musical” (Ribas, 2008) entre pessoas de diferentes idades e gerações.

O diferenciar-se em relação aos adultos pode acontecer, também, pela intensidade com que os jovens ouvem música (Schmeling, 2005, p. 74-75). Como Green lembra, as preferências musicais dos jovens estão ligadas a gêneros musicais que para eles possuem um significado relacionado à liberdade de expressão e de mudança. Isto é, a relação que mantêm com a música representa uma manifestação de uma identidade cultural caracterizada por dupla pertença: classe de idade e do meio social (Green, 1987, p 100).

A música como elemento de diferenciação de classe, aparece em vários depoimentos de jovens, especialmente quando associam repertório e gêneros musicais. Isto é percebido quando são indicadas músicas que revelam as diferentes preferências ligadas às significações étnico-raciais, por exemplo. O mesmo pode também ser mencionado quando se verifica que uma dada música é escolhida como tendo uma forte significação diferenciadora e com "marcas" identitárias. Os jovens identificam-se e se auto-referenciam com os de "sua idade", seu grupo ou sua galera, por ouvirem ou curtirem as mesmas músicas e terem os mesmos gostos e escolhas musicais.

\section{Considerações finais}

Intentamos, neste artigo, mostrar alguns aspectos que permitem pensar na importância de falar em juventudes nessa interface com música, socialização e identidades. Quando nos referimos à juventude, procuramos compreendê-la como uma categoria sócio-história, propondo um alargamento do olhar para além da juventude como categoria física e com delimitações e critérios biológicos e etários. 
Buscou-se também uma análise da socialização e identidades como categorias que também se movem e que quando interpostas com música e mídias não devem ser vistas como imutáveis ou fixas. Ao abordar o tema, procuramos atualizar as ferramentas de análise para interpretar práticas musicais que se renovam permanentemente com os meios de comunicação. Diferente da noção de "tribos" que remete a território e etnicidade, as redes virtuais conduzem a outros modos de agrupamentos mais flexíveis, mais instáveis (Garcia Canclini e Urteaga, 2012).

Pode-se, então dizer que a mídia desempenha um papel importante nos processos de identidade e formação musical. Vale ressaltar a competência dos jovens para refletir sobre os discursos mediados e as representações das músicas que eles consomem, mostrando quanto se envolvem com as mídias.

Para os jovens o uso das mídias mostra-se tanto como um meio que os ajuda na construção de sua identidade como uma espécie de companhia que thes dá segurança no seu posicionamento na vida cotidiana. Além da música poder ter efeitos agregadores, através dos elementos emocionais e afetivos presentes nas produções artístico-musicais, ela também colabora na identificação de grupos juvenis. Isto se dá pelo destaque que é mencionado pelos jovens ao relatarem suas preferências musicais cujas características revelam valores, tradições e ideologias que são musicalmente compartilhadas no cotidiano. A música também informa sobre novos estilos de vida, modas, formas de conduta, servindo de estímulo para sonhos e anseios próprios e, com tudo isso, colaborando para construir identidades no âmbito individual e coletivo, assim como na vida pública e privada.

Se a relação juventude, música, mídia é vista quase que "natural" diante da centralidade que os meios de comunicação ocupam na vida cotidiana, é tarefa nossa como educadores dar visibilidade ao seu papel na "construção de sujeitos autônomos e conscientes, embora isso não necessariamente implique em um quadro de suavidade ou ausência de tensões" (Rocha, 2012, p. 239), como visto em alguns relatos.

Assim, ao se examinar expressões musicais que os jovens constroem em seu cotidiano surgem diferentes aspectos inspiradores para se possa pensar a juventude no plural. Isso significa compreender jovens como sujeitos capazes de 
atuar nas diferentes dimensões da vida em sociedade como no trabalho, na família e no lazer. Nos últimos anos tem havido no Brasil uma ênfase das políticas públicas em valorizar a juventude e sua emergência como categoria social ativa, com possibilidades de contribuição no cenário sócio-político e incremento do protagonismo juvenil.

Buscar compreender a vida dos jovens, seu cotidiano, o que representa seu mundo e seu tempo são desafios a serem enfrentados quando se tem a perspectiva de que os conhecimentos também podem contribuir para mudanças e melhoria no mundo atual. Para tanto tentamos buscar um enfoque analítico multidimensional no qual os olhares de especialistas sobre juventude, dos estudos da comunicação, da música, da educação, se entrecruzam para, de modos distintos, nos aproximarmos de práticas musicais midiatizadas feitas por jovens.

\section{Referências}

ARNETT, Jeffrey Jensen. Adolescents' uses of media for self socialization. Journal of Youth and Adolescence. v.5, n. 24, p. 519-533, 1995.

ARROYO, Margarete. Juventudes, músicas e escolas: análise de pesquisas e indicações para a área da educação musical. Revista da ABEM, Porto Alegre, n. 21 , p. 53-66, março 2009.

ARROYO, Margarete (Org.). Jovens e músicas: um guia bibliográfico. São Paulo: Editora UNESP, 2013.

ARROYO, Margarete, JANZEN, Thenille Braun. O estado do conhecimento do campo temático juventude, música e escola: resultados iniciais In: Congresso da ANPPOM, 17. 2007, São Paulo. Anais ... São Paulo: ANPPOM UNESP, 2007. p. $1-12$.

BAACKE, Dieter (Org.) Handbuch Jugend und Musik. Opladen: Leske and Budrich, 1998.

BARBOSA, Lívia; VELOSO, Letícia; DUBEUX,Veranise. Música e Juventude: a trilha sonora do cotidiano jovem brasileiro. In: BARBOSA, Lívia. (Org.). Juventudes e Gerações no Brasil Contemporâneo. Porto Alegre: Sulina, 2012. p. 31-60.

BERGER, Peter; LUCKMANN, Thomas. A construção social da realidade: tratado de sociologia do conhecimento. 6. ed.,Tradução Floriano de Souza Fernandes. Petrópolis: Vozes, 1985.

BOURDIEU, Pierre. Cuestiones de sociologia. Tradução Enrique Martín Criado. Madrid: Istmo, 2000. 
CARRANO, Paulo César Rodrigues. Juventudes: as identidades são múltiplas. Movimento: Revista da Faculdade de Educação da UFF, Rio de Janeiro, n. 1, p. 11 27, maio 2000.

CASTRO, Gisela Grangeiro da Silva. Música, juventude e tecnologia: novas práticas de consumo na cibercultura. Logos: Comunicação \& Universidade, Rio de Janeiro, Ano 14, n. 26, p. 58-69, $1^{\circ}$ semestre 2007.

DAYRELL, Juarez. A música entra em cena: O rap e o funk na socialização da juventude. Belo Horizonte: Editora da UFMG, 2005.

FREITAS, Maria de Fatima Quintal de. Juventude e Vida Cotidiana: Perspectivas da Psicologia Social Comunitária. In: CASTRO, L. Rabello de; BESSET, VeraLopes (Orgs.), Pesquisa-Intervenção na Infância e Juventude, Río de Janeiro, NAU /Faperj, 2008a. p. 62-84.

FREITAS, Maria de Fatima Quintal de. Estratégias de ação comunitária e mudança social: relações a partir da vida cotidiana e dos processos de participação. In: DIMENSTEIN, M. (Org.). Psicologia social comunitária: aportes teóricos e metodológicos. Natal: EDUFRN, 2008b. p. 23-42.

GARCIA CANCLINI, Néstor; CRUCES, Francisco; CASTRO POZO, Maritza Urteaga (Coords.). Jóvenes, culturas urbanas y redes digitales. Buenos Aires: Ariel, 2012.

GARCIA CANCLINI, Néstor; URTEAGA, Maritza (Coords.). Cultura y desarrollo: una visión crítica desde los jóvenes. Buenos Aires: Paidós, 2012.

GREEN, Anne-Marie. Les comportements musicaux des adolescentes. Inharmoniques "Musiques, Identités", v. 2, p. 88-102, 1987.

GROPPO, Luis Antonio. Condição juvenil e modelos contemporâneos de análise sociológica das juventudes. Ultima Década, Valparaíso, n. 33, p. 11-36, deciembre 2010.

HAYASHI, Maria Cristina; HAYASHI, Carlos Roberto Hayashi, MARTINEZ, Claudia Maria. Estudos sobre jovens e juventude: diferentes percursos refletidos na produção científica brasileira. Educação, Sociedade \& Culturas, n² 27, p. 131-154, 2008.

HERSCHMANN, Michael. Abalando os anos 90: Funk, hip hop, globalização, violência e estilo cultural. Rio de Janeiro: Rocco, 1996.

JANZEN, Thenille Braun. Juventude e música: a produção nos cursos de pósgraduação brasileiros. In: Encontro Anual da ABEM e Congresso Regional da ISME na América Latina, 16/4, 2007, Campo Grande. Anais... Salvador: ABEM, 2007. p. $1-9$.

KÜBLER, H. D. Leben mit der Hydra. Die Medienwelten von Kindern und Jugendlichen. In: FRITZ, Jürgen; FEHR, Wolfgang (Org.). Computerspiele: Virtuelle Spiel-und Lernwelten. Bonn: Bundeszentrale für Politische Bildung, 2003. p. 1-26.

LANE, Silvia T. M. A psicologia social e uma nova concepção de homem para a psicologia. In: LANE, S. T. M.; CODO, W. (Orgs.), Psicologia social: o homem em movimento. 4a. ed. São Paulo: Brasiliense, 1986a. p. 10-20. 
LANE, Silvia T. M. O processo grupal. In: LANE, S. T. M.; CODO, W. (Orgs.), Psicologia social: o homem em movimento. 4a. ed. São Paulo: Brasiliense, 1986b. p. 78-98.

LIMA, Ari. Funkeiros, Timbaleiros e Pagodeiros: Notas Sobre Juventude e Música Negra na Cidade de Salvador. Cadernos CEDES, Camponas. v. 22, n. 57, p. 77-96, agosto 2002. Disponível em:http://www.scielo.br/scielo.php?script $=$ sci _arttext\&pid=S0101-32622002000200006. Acesso: 13 jun. 2014.

MacDONALD, Raymond; HARGREAVES, David; MIELL, Dorothy (Org.). Musical Identities.Oxford: Oxford University Press, 2009.

MAHEIRIE, Kátia; GROFF, Apoliana Regina; BUENO, Gabriel Bueno; MATTOS, Laura Kemp de; SILVA. Dâmaris Oliveira Batista da Silva; MÜLLER, Catarina Flora Lorena. Concepções de juventude e política: Produção acadêmica em periódicos científicos brasileiros (2002 a 2011). Estudos de Psicologia, Natal, v. 2, n. 18, p. 335-342, abril-junho 2013.

MARGULIS, Mario e URRESTI, Marcelo. La juventud es más que una palabra. In: Margulis, M. (Org.). La juventud es más que una palabra. Buenos Aires: Biblos, 1996. p. 13-30.

MENANDRO, Maria Cristina. S.; TRINDADE, Zeidi, Algumas questões preliminares no estudo da adolescência/juventude. In: TRINDADE, Zeidi A.; MENANDRO, M. Cristina S.; SOUZA, Lídio de; CORTEZ, Mirian B. (Orgs.), Juventude, masculinidade e risco. Vitória: GM Gráfica e Editora, 2009. p. 13-37.

MENANDRO, Maria Cristina S.; TRINDADE, Zeidi e ALMEIDA, Angela M. Oliveira. Gente jovem reunida: representações sociais de adolescência/juventude em textos jornalísticos. Vitória: UFES/ GM Gráfica e Editora, 2010.

MOURA, Auro Sanson. Música e construção de identidade na juventude: o jovem, suas músicas e relações sociais. Dissertação (mestrado) - Universidade Federal do Paraná, Setor de Ciências Humanas, Letras e Artes, Programa de Pós-Graduação em Música. Curitiba, 2009.

MÜNCH, Thomas. Jugend, Musik und Medien. In: BAACKE, Dieter (Org.). Handbuch Jugend und Musik. Opladen: Leske and Budrich, 1998. p. 383-400.

NASCIMENTO, Thaís Vieira do. Juventudes e músicas: uma bibliografia comentada de dissertações e teses defendidas no Brasil entre 1996 e 200. In: Encontro Anual da ABEM. 16,2008, São Paulo. Anais...Salvador: ABEM, 2008. p. 1-8.

NASCIMENTO, Thais Vieira do; ARROYO, Margarete. Juventudes e músicas abordadas nos trabalhos de Pós-Graduação brasileiros: 1996 a 2008. Anais da $4^{a}$ Semana do Servidor e $5^{a}$ Semana Acadêmica, Uberlândia, 2008, p. 1-11.

OLIVEIRA, Vilmar Pereira de. A influência do gosto musical no processo de construção da identidade na juventude. Disponível em http://www.psicologia.pt/artigos/ver_artigo.php?codigo $=$ A0661 2012. Acesso em 15 jun de 2014. 
QUARESMA, Maria Luísa. Práticas culturais dos jovens das classes sociais dominantes: reflexões em torno do ecletismo cultural. Forum Sociológico, n. 23 , p. 31-39, 2013.

RIBAS, Maria Guiomar. Co-educação musical entre gerações. In: SOUZA, J. Aprender e ensinar música no cotidiano. Porto Alegre: Sulina, 2008. p. 143-166.

ROCHA, Rose Maria de Melo. Juventudes, comunicação e consumo: visibilidade social e práticas narrativas. In: BARBOSA, Lívia. (Org.). Juventudes e Gerações no Brasil Contemporâneo. Porto Alegre: Sulina, 2012. p. 238-276.

SCHLÄBITZ, Norbert. Der diskrete Charme der neuen Medien: Digitale Musik im medientheoretischen Context und deren musikpädagogisch Wertung. Augsburg: Bernd Wisner, 1996.

SCHMELING, Agnes. Cantar com as mídias eletrônicas: um estudo de caso com jovens. Dissertação (Mestrado em Educação Musical) - Instituto de Artes, Universidade Federal do Rio Grande do Sul, Porto Alegre, 2005.

SETTON, Maria da Graça J.. Família, escola e mídia: um campo com novas configurações. Educação e pesquisa, janeiro-junho, ano/vol. 28, n. 001, USP, São Paulo, p. 107-116, 2002.

SETTON, Maria da Graça J. Experiências de socialização e disposições híbridas de habitus. In DAYRELL, J.; NOGUEIRA, M. A.; RESENDE, J. M.; VIEIRA, M. M. (Orgs.). Família, escola e juventude: Olhares cruzados Brasil-Portugal. Belo Horizonte: Editora da UFMG, 2012. p. 38-55.

SOUZA, Jusamara. Educação musical e práticas sociais. Revista da ABEM, Porto Alegre, v. 10, p. 38-44, março 2004.

SOUZA, Jusamara. Educação musical e culturas juvenis: Socialização musical, nova oralidade e outras aprendizagens mediadas pela tecnologia. Projeto de pesquisa, 2008. (mimeo)

SOUZA, Jusamara. Educação musical de jovens entre diferentes instâncias de socialização e ensino-aprendizagem: um estudo exploratório. In: Conferencia Regional Panamericana / Conferencia Norteamericana/ Conferencia Latinoamericana.1/ 1/ 8, 2011,Tabasco, Mexico, Anais...Tabasco: ISME, 2011a, p. $1-9$.

SOUZA, Jusamara. Youth, musical education and media: Singularities of learning mediated by technology. Action, Criticism, and Theory for Music Education. v. 10. n.1, p. 94-113, 2011b. Disponível em: http://act.maydaygroup.org/ articles/Souza10_1.pdf. Acesso em: 13 jun.2014.

SPÓSITO, Marilia (Coord.). Estado da Arte sobre juventude na pós-graduação brasileira: educação, ciências sociais e serviço social (1999-2006), volume 1. Belo Horizonte: Argvmentvm, 2009.

STÅLHAMMAR, Börje. Music-their lives: The experience of music and view of music of a number of Swedish and English young people. Action, Criticism, and 
Theory for Music Education, v. 3, n. 2, p. 1-31, 2004. Disponível em: http://act.maydaygroup.org/articles/Stalhammar3_2.pdf. Acesso em: 11 jun. 2014.

TAJFEL, Henri. Grupos humanos e categorias sociais. Lisboa: Livros Horizontes, 1983.

THOMPSOHN, John. A mídia e a modernidade: uma teoria social da mídia. Petrópolis: Vozes, 1998.

VOLLBRECHT, Ralf.; FERCHHOFF, Wiefried.; BAACKE, Dieter. Kinder und Jugendliche in medialen Welten und Netzen. Prozesse der Mediensozialisation. In: FRITZ, Jürgen; FEHR, Wolgang (Org.). Handbuch Medien: Computerspiele. Bonn, 1997. p. 31-57. Disponível em: <http://www.mediaculture-online.de>. Acesso em: 7 jan. 2005.

WELLER, Wivian. A presença feminina nas (sub)culturas juvenis: a arte de se tornar visível. Revista Estudos Feministas, Florianópolis, vol. 13, n. 1, p. 107-126, 2005.

WILDERMUTH, Norbert; DALSGAARD, Anne Line. Imagined futures, present lives: youth, media and modernity in the changing economy. Young, 14, p. 9-31, 2006.

ZANELLA, Andréa Vieira, GROFF, Apoliana Regina Groff; SILVA, Dâmaris Oliveira Batista da; MATTOS, Laura Kemp de; FURTADO, Janaína Rocha; ASSIS, Neiva de. Jovens, juventude e políticas públicas: Produção acadêmica em periódicos científicos brasileiros (2002 a 2011). Estudos de Psicologia, Natal, v. 2, n. 18, p. 327-333, abril-junho 2013. 